Check for updates

Cite this: RSC Adv., 2019, 9, 35033

\title{
Development of miniaturized fluorimetric device for caffeine determination using a smartphone $\uparrow$
}

\author{
Natália da Costa Luchiari, Gabrielen Alves da Silva, César Augusto Marasco Júnior \\ and Paulo Clairmont Feitosa de Lima Gomes (iD*
}

Caffeine is an element that is consumed worldwide. It is present in many products such as beverages, chocolate, coffee, tea, energy drinks and medicines. Portable 3D devices working together with colorimetric and fluorimetric reactions have been able to determine the presence of caffeine in different kinds of samples. Also, digital image-based methods using smartphones have conferred portability and accessibility to miniaturized devices that are innovative and promising options for quick and low cost analyses. This study proposes a miniaturized fluorimetric device to determine caffeine by digital image using a smartphone. The OpenCamera app was used to capture images that were processed using ImageJ software to obtain RGB channels values. The red (R) channel signal intensity was selected as the analytical response. The device developed was applied to determine caffeine in an energy drink and medicines. The method developed presented a linear range from 100 to $600 \mathrm{mg} \mathrm{L}^{-1}$ of caffeine, and quantification (LOQ) and detection (LOD) limits of $100 \mathrm{mg} \mathrm{L}^{-1}$ and $30.0 \mathrm{mg} \mathrm{L}^{-1}$, respectively. The caffeine concentration found in the products analyzed was $328 \mathrm{mg} \mathrm{L}^{-1}( \pm 2.5 \%)$ for the energy drink, $345 \mathrm{mg} \mathrm{L}^{-1}( \pm 15 \%)$ for medicine $A$ and $322 \mathrm{mg} \mathrm{L}-{ }^{1}( \pm 7.3 \%)$ for medicine $B$. The proposed device presented important characteristics such as low cost, required small volumes of reagents and samples, quick analysis, portability and suitable to be applied in complex matrices.

Received 9th August 2019
Accepted 6th October 2019

DOI: $10.1039 / c 9 r a 06220 c$

rsc.li/rsc-advances
Nowadays, liquid chromatography coupled to sequential mass spectrometry (LC-MS/MS) is the technique of choice to determine caffeine in many analytical matrices. However, this and the other techniques aforementioned are not portable and require trained professionals, solvent consumption and sample pretreatment procedures. In turn, electronic and digital devices have become powerful and useful tools for analytical chemistry allowing the emergence of methods based on digital images for the acquisition of qualitative and quantitative information of a target analyte, in place of some high cost instrumental techniques like LC-MS/MS., ${ }^{7,8}$

Digital image analysis methods are based on the use of a digital sensor like digital cameras, smartphones, scanners and others used to capture images resulting from colorimetric/ fluorimetric reactions and posterior conversion of these images into measurable data, such as values of the primary colors red $(\mathrm{R})$, green (G) and blue (B) in the RGB approach as suggested by the International Color Consortium (ICC). ${ }^{8,9}$

The literature shows smartphone devices are being used in different proposals, such as detection of bisphenol $\mathrm{A}$ in water samples, ${ }^{\mathbf{1 0}}$ determination of ascorbic acid in fruits, ${ }^{\mathbf{1 1}}$ color in honey, ${ }^{12}$ captopril in dosage forms,${ }^{7}$ sulfite in beverages, ${ }^{9}$ copper in sugar cane spirits ${ }^{\mathbf{1 3}}$ and formaldehyde in cosmetics. ${ }^{8}$

These colorimetric and fluorimetric reactions allied to the development of 3D printed microsystems have shown promise and a trend towards chemical analysis due to its easy
Department of Analytical Chemistry, Unesp, National Institute for Alternative Technologies of Detection, Toxicological Evaluation and Removal of Micropollutants and Radioactives (INCT-DATREM), Institute of Chemistry, P.O. Box 355, 14800-900 Araraquara (SP), Brazil.E-mail: paulo.clairmont@unesp.br

$\dagger$ Electronic supplementary information (ESI) available. See DOI: 10.1039/c9ra06220c 
implementation and increased analytical frequency that favor a more accessible and easy method to be executed. Furthermore, the amounts of samples and reagents are reduced, as well as the analysis time, the chemical residues, and occupational exposure of the analyst, which makes the colorimetric and fluorimetric reactions a suitable alternative for quick and low cost analysis. ${ }^{\mathbf{1 4 , 1 5}}$

For the caffeine detection in aqueous samples by digital image methods, a fluorimetric reaction with the fluorescent dye 8-hydroxypyrene-1,3,6-trisulfonate (HPTS) could be used, as previously published by Rochat et al. ${ }^{16}$ The reaction mechanism involves the formation of a charge transfer complex, from the interaction between caffeine and HPTS, that has fluorescence properties in the visible ultraviolet (UV-VIS) region.

The reaction in miniaturized scale and the use of smartphones have shown a strong trend towards analysis using spottests for varied kinds of chemical reactions, making it possible to perform in loco analysis. Thus, the aim of this research is to develop a portable, easy and low cost device for caffeine determination in energy drinks and medicines.

\section{Experimental}

\subsection{Chemicals and samples}

Caffeine standard (MM $194.19 \mathrm{~g} \mathrm{~mol}^{-1}$, CAS 58-08-2) and HPTS (MM $524.39 \mathrm{~g} \mathrm{~mol}^{-1}$, CAS 6358-69-6) were purchased from Sigma-Aldrich®. Caffeine stock solutions were prepared at the concentration of $2000 \mathrm{mg} \mathrm{L}^{-1}$ in ultrapure water. The buffer solution was prepared from aqueous solutions of $1.00 \mathrm{~mol} \mathrm{~L}^{-1}$ of monobasic potassium phosphate $\left(\mathrm{KH}_{2} \mathrm{PO}_{4}, \mathrm{MM} 136.09 \mathrm{~g} \mathrm{~mol}^{-1}\right.$, CAS 7778-77-0) and dibasic potassium phosphate $\left(\mathrm{K}_{2} \mathrm{HPO}_{4}{ }^{-}\right.$ $\cdot 3 \mathrm{H}_{2} \mathrm{O}, \mathrm{MM} 174.18 \mathrm{~g} \mathrm{~mol}^{-1}$, CAS 7758-11-4) both purchased from Sigma-Aldrich ${ }^{\circledR}$. The HPTS stock solution was prepared at the concentration of $100 \mu \mathrm{mol} \mathrm{L}{ }^{-1}$ in phosphate buffer solution of $0.100 \mathrm{~mol} \mathrm{~L}^{-1}$ at $\mathrm{pH}$ 6.3. Working standard solutions were prepared weekly and stored in an amber bottle in a refrigerator at $4{ }^{\circ} \mathrm{C}$. The standard stock solutions used in this study were prepared using ultrapure water (resistivity $<18.2 \mathrm{M} \Omega \mathrm{cm}$ at 298 K) from a Milli-Q water system (Synthesis MILLIPORE). Three samples were analyzed by the proposed method: an energy drink commercial sample, acquired from a market located in Araraquara, SP-Brazil, and two medicine samples purchased from a drugstore in the same city. According to the labels, these three samples contained caffeine in their composition.

\subsection{Instrumentation}

The reference method was developed in a spectrofluorimeter RF-1501 (Shimadzu Corporation, Tokyo, Japan). The scanning range was 480-700 $\mathrm{nm}$, with emission and excitation wavelengths at $509 \mathrm{~nm}$ and $460 \mathrm{~nm}$, respectively. The volume of 1500 $\mu \mathrm{L}$ of sample containing caffeine was reacted with the same volume as the fluorophore prepared in buffer solution.

The portable system was developed using a 3D Cloner ST printer (Ind. Schumacher Ltda., Marechal Cândido Rondon-PR, Brazil) for analysis of fluorescence decay reactions in reduced sample volumes. The external structure of the device body was printed in black PLA (polylactic acid). An insert was used as the analytical bucket for this system. An optical fiber $(1.00 \times 20.0$ $\mathrm{mm}$ ) was used to direct the light generated by the blue lightemitting diode (LED) source to the wall of the bucket. The LED was connected to an Arduino nano microcontroller system (Atmega 328, Arduino, USA). An adjustable resistor (potentiometer) of $100 \mathrm{k} \Omega$ that divides the voltage of the system was used to control the radiation intensity of the system. The system was powered by an OTG cable that connects the Arduino to the smartphone Motorola Moto G5 Plus which used its battery as the power supply.

\subsection{Data analysis}

2.3.1 Image acquisition using OpenCamera app. The image acquisition step was performed using a smartphone Motorola Moto G5 Plus XT, with $12 \mathrm{Mpx}$ rear camera (dual autofocus pixel). OpenCamera app (version 1.40) was used in this step in order to setup the flash, filters and scale adjustment as demonstrated in Table S1 in the ESI. $\dagger$ The capture mode was manually adjusted.

2.3.2 Image processing using ImageJ. For image processing, the freely-available ImageJ software (version 1.50i, National Institutes of Health, USA) (https://imagej.nih.gov/ij/index.html) was used to obtain RGB channel intensities, according to the procedure of Abràmoff, Magalhães and Ram. ${ }^{17}$ Fig. 1 illustrates representatively the proposed portable device and the software Image J with the captured image and the three color channels of the RGB Model.

To ensure that the same region was analyzed a region of optical interest (ROI) was defined and applied. This tool ensures that the area analyzed shows fixed values and, consequently, repeatability and reliability. The analytical signal was converted to optical density (O.D.) and, then, was calculated using the equation:

$$
\text { O.D. }=-\log \frac{R}{R_{0}}
$$

where $R_{0}$ and $R$ are the signal intensity values of the red channel for the blank and the sample, respectively.

\subsection{Figures of merit}

The methods in this study were validated according to parameters of precision (intra-day and inter-day), limit of quantification

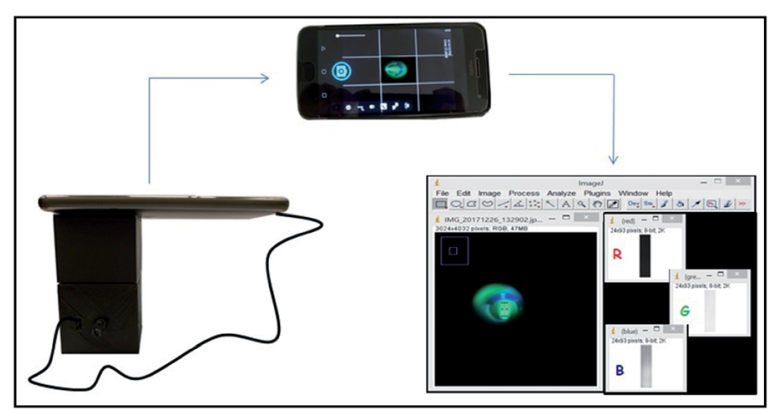

Fig. 1 Schematic representation of the fluorimetric device, image acquisition and processing step. 
(LOQ), limit of detection (LOD), sensitivity and linearity. LOD was determined by the ratio between LOQ and a factor 3.30 representing the lowest concentration value for the analyte to be accurately detected by an analytical method. LOQ was determined as the lowest analyte concentration at which it was possible to quantify with specified precision (\% RSD less than 20.0\%), which was the first point of the analytical curve in agreement with the Food and Drug Administration (FDA $)^{18}$ and International Council for Harmonization of Technical Requirements for Pharmaceuticals for Human Use (ICH) ${ }^{19}$ Linearity was obtained by spiking the samples of interest at increasing concentrations of caffeine for a range of 100 to $600 \mathrm{mg} \mathrm{L}^{-1}(n=5)$ in the reference and proposed methods. Sample analyses by the standard addition method were performed in triplicate $(n=3)$ and the means of the values were obtained as analytical responses. The sensitivity was obtained by the calibration curve slope. Intra- and inter-day precision of the methods were evaluated based on the relative standard deviation (\% RSD) from the calibration curve performed in triplicate.

\subsection{Application of the proposed method}

The reference and proposed methods were applied to one sample of energy drink and two samples of medicines. Matrix effects and sample dilutions were evaluated for each one. Among many strategies to evaluate the matrix effect, it was chosen to compare the analytical curve slope obtained in the blank sample (solvent) to the matrix after a dilution to achieve $1.00 \mathrm{mg} \mathrm{L}^{-1}$ where there was no caffeine analytical signal. ${ }^{20}$ The matrix effect was evaluated using the following equation suggested by Gros, Rodríguez-Mozaz and Barceló: ${ }^{21}$

$$
\% \text { matrix effect }=\frac{\left(\delta_{\text {matrix }}-\delta_{\text {solvent }}\right)}{\delta_{\text {solvent }}} \times 100
$$

For the reference method, the energy drink sample was diluted to $1.00 \mathrm{mg} \mathrm{L}^{-1}$ and standard additions from 100 to $600 \mathrm{mg} \mathrm{L}^{-1}$ were performed. The same previous procedure was applied in the fluorimetric device. Similarly, standard addition calibration was performed to determine caffeine in the medicines using both the reference and proposed methods. For the analysis, an energy drink solution was prepared with caffeine concentration of $300 \mathrm{mg} \mathrm{L}^{-1}$. The same process was undertaken for the medicines samples. Solutions of these medicines were prepared in ultrapure water and, before the use, were filtered using a $0.45 \mu \mathrm{m}$ filter.

\section{Results and discussion}

\subsection{Development of the reference method}

3.1.1 Intensity evaluation. The reference method developed in ultrapure water showed fluorescence quenching, increasing caffeine concentration decreases the fluorescence intensity. This reaction occurred according to the Stern-Volmer kinetic model $^{22,23}$ that described the fluorescence dynamic suppression depending on the mutual collision between the excited molecule (HPTS) and the suppressor (caffeine). The quenching effect observed during the experiments can be see in Fig. 2 .
As observed in Fig. 2, the interaction between HPTS and caffeine was observed at a concentration ranging from 100 to $600 \mathrm{mg} \mathrm{L}^{-1}$ in ultrapure water. The excitation spectrum at $460 \mathrm{~nm}$ showed the highest emission signal at $509 \mathrm{~nm}$. The maximum fluorescence intensity was observed close to 400 a.u. values. Therefore, HPTS proved to be a potential alternative for the caffeine determination.

3.1.2 Validation of the reference method. The matrix effect could impair the reaction between caffeine and HPTS, then, the method validation, through the standard addition or matrixmatching calibration, is an important step in that study to prevent errors and the lack of precision. Linearity was evaluated through spiking caffeine from 100 to $600 \mathrm{mg} \mathrm{L}^{-1}$ in ultrapure water. The linear model presented a slope and linear intercept with a correlation coefficient $\left(R^{2}\right)$ of 0.994 , as can be seen in Fig. 3.

Analysis of variance (ANOVA) was applied to the spectrofluorimetric method data and demonstrated linearity without lack-of-fit. Intra-day precision was 0.660 to $1.56 \%$ and inter-day precision was 1.12 to $2.36 \%$ both in the same concentration range. LOD and LOQ of the reference method were 30.0 and $100 \mathrm{mg} \mathrm{L}^{-1}$, respectively.

\subsection{Development of portable fluorimetric device method}

3.2.1 Optimization of the reaction conditions. In a previous evaluation, the reaction viability was studied based on an analytical visual answer between equal volumes of aqueous caffeine solution (100 $\left.\mathrm{mg} \mathrm{L}^{-1}\right)$ and the buffer phosphate solution $\left(0.100 \mathrm{~mol} \mathrm{~L}^{-1}, \mathrm{pH} 6.30\right)$ that contained 100 $\mu \mathrm{mol} \mathrm{L}{ }^{-1}$ of HPTS. The system was irradiated by a blue colored RGB source of wavelength around $460 \mathrm{~nm}$ and the volumes were fixed as $50.0 \mu \mathrm{L}$ for both solutions, totalling $100 \mu \mathrm{L}$ final volume. The irradiation used a support spot-test of a 3D printed PLA plate. The reaction occurred in a flat bottom insert (ID 24701, Supelco, Sigma-Aldrich () with a maximum capacity of $300 \mu \mathrm{L}$ (dimensions $5.00 \times 31.0 \mathrm{~mm}$ ) and the reaction time was maintained as 4 minutes. The results of the optimized conditions, according to the caffeine concentration, can be see in Fig. 4.

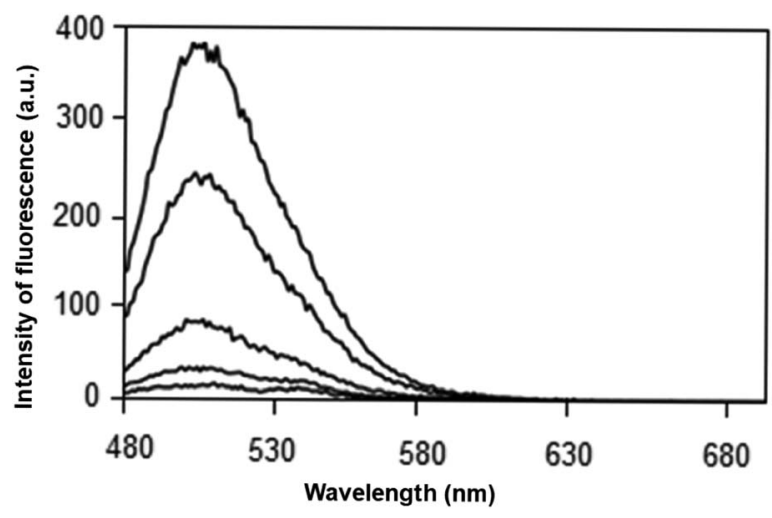

Fig. 2 Emission spectrum at $460 \mathrm{~nm}$ for caffeine solution in water at concentrations of $0,100,220,530$ and $600 \mathrm{mg} \mathrm{L}^{-1}$. 


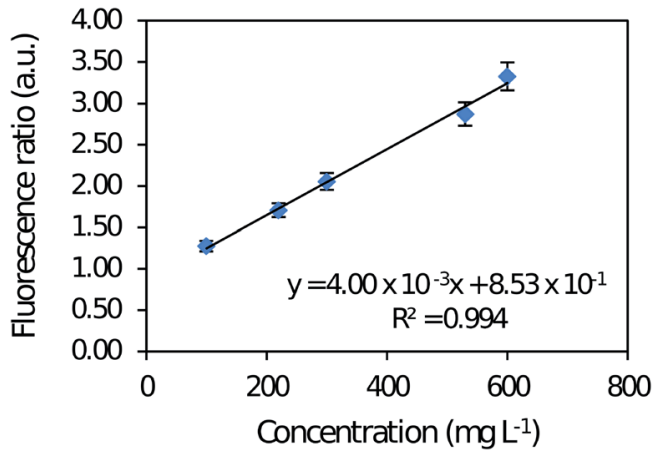

Fig. 3 Analytical curve of caffeine in aqueous solution with a concentration range varying from 100 to $600 \mathrm{mg} \mathrm{L}^{-1}$, in spectrofluorimeter RF-1501.

3.2.2 Validation of the proposed method. The color of the image captured by the smartphone camera was green fluorescence. The ImageJ software provided the signal intensities of the RGB channels according to the region of interest (ROI) that was selected. The red (R) channel of the RGB color model was chosen given that it is a complementary color and the signal intensity increases as the caffeine concentrations increased. In order to avoid errors in the image treatment, the ROI was inserted in a fixed position in the bucket, as well as the smartphone support, ensuring the same region of each image was captured and analyzed. Linearity was observed for spiking caffeine in ultrapure water at concentrations of 100 to $600 \mathrm{mg} \mathrm{L}^{-1}$. The linear relationship obtained between the O.D. and caffeine concentrations in water corresponds to $R^{2}$ of 0.996 and $y=100 \times 10^{-4} x+163 \times 10^{-2}$. ANOVA was also applied which demonstrated a linearity without lack-of-fit. The intra-day precision was 0.100 to $0.610 \%$ and the inter-day precision was 0.340 to $0.670 \%$ both in that same concentration range. LOD and LOQ of the reference method were 30.0 and $100 \mathrm{mg} \mathrm{L}^{-1}$, respectively.

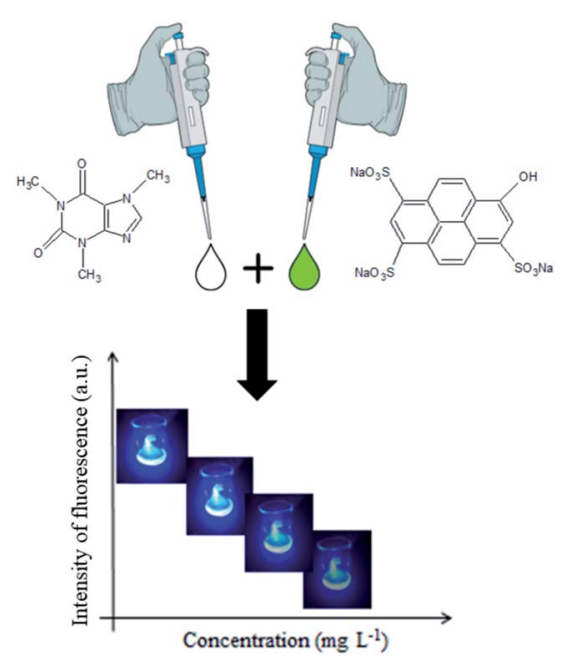

Fig. 4 Schematic diagram of the fluorimetric reaction between caffeine (left) and HPTS (right) resulting in a product fluorescence intensity varying with caffeine concentration.

\subsection{Comparison between the methods}

According to the results obtained for both methods, a comparison regarding the figures of merit is presented in Table 1.

Both methods did not present variations in the values obtained for the LOQ and LOD. In both methods, the linear range of the study was the same, and for the proposed method there was no loss of linearity, demonstrating an advantage of the proposed device, since the literature reports loss of linearity for bands greater than 100 units of concentration in studies involving image acquisition. ${ }^{\mathbf{2 4 , 2 5}}$ Furthermore, the proposed method was shown to be applicable and precise for caffeine determination in real samples, with a relative standard deviation (\% RSD) intra-day and inter-day lower than $1.00 \%$.

\subsection{Determination of caffeine in commercial samples}

After the validation, the portable method proved to be adequate for quantifying caffeine in medicines and the energy drink in a linear range of 100 to $600 \mathrm{mg} \mathrm{L}^{-1}$. Therefore, Table 2 shows the caffeine concentrations in the studied samples as well as their respective analytical curves and measured relative error in the matrices.

The caffeine concentration expected in each sample was $300 \mathrm{mg} \mathrm{L}^{-1}$. The proposed method obtained a relative error of lower than $15 \%$ for the energy drink and medicine samples demonstrating the proposed method has suitable precision and accuracy for this analysis.

The energy drink and medicine samples have different compositions; those components could affect the interaction of caffeine and HPTS, in addition to the fluorescence signal. The standard addition was done for both samples in order to minimize this effect. Although, the samples were diluted to $1.00 \mathrm{mg} \mathrm{L}^{-1}$ of caffeine for analysis, there was a matrix effect. The matrix effect obtained for medicine samples A and B compared to the analytical curve slope performed in ultrapure water demonstrated a signal suppression of 20 and $60 \%$. There was analytical signal suppression since HPTS could interact with the sample components and was less available to react with caffeine.

The samples analyzed using the fluorimetric device and spectrofluorimeter were compared through test- $F$ and test- $t$ at $95 \%$. The $F$-test presented $p$-value $(0.466)>\alpha(0.0500)$ which means the samples present equivalent variances. Thereafter, the $t$-test

Table 1 Figures of merit for fluorimeter and portable fluorimetric device

\begin{tabular}{lll}
\hline Analytical parameters & $\begin{array}{l}\text { Fluorimeter } \\
\text { Ultrapure water }\end{array}$ & $\begin{array}{l}\text { Fluorimetric device } \\
\text { Ultrapure water }\end{array}$ \\
\hline Linear range $\left(\mathrm{mg} \mathrm{L}^{-1}\right)$ & $100-600$ & $100-600$ \\
LOQ $\left(\mathrm{mg} \mathrm{L}^{-1}\right)$ & 100 & 100 \\
LOD $\left(\mathrm{mg} \mathrm{L}^{-1}\right)$ & 30 & 30 \\
RSD intraday (\%) & $0.660-1.56$ & $0.100-0.610$ \\
RSD interday (\%) & $1.12-2.36$ & $0.340-0.670$ \\
Sensitivity & $4.00 \times 10^{-3}$ & $1.00 \times 10^{-4}$ \\
Linear coefficient & $8.53 \times 10^{-1}$ & $1.63 \times 10^{-2}$ \\
$R^{2}$ & 0.994 & 0.996 \\
Reaction time (minutes) & 4 & 4
\end{tabular}


Table 2 Concentrations obtained for energy drink and medicines A and B using the respective analytical curves as the analytical model

\begin{tabular}{llll}
\hline Matrix & Analytical curve & $R^{2}$ & $C_{300}\left(\mathrm{mg} \mathrm{L}^{-1}\right)$ \\
\hline Energy drink & $y=7.00 \times 10^{-5} x+9.25 \times 10^{-2}$ & 0.985 & 328 \\
Medicine A & $y=8.00 \times 10^{-5} x+7.74 \times 10^{-2}$ & 0.989 & 345 \\
Medicine B & $y=4.00 \times 10^{-5} x+7.91 \times 10^{-2}$ & 0.995 & 322
\end{tabular}

Table 3 Comparison of the main analytical parameters of the present study with the literature

\begin{tabular}{|c|c|c|c|c|}
\hline References & \multicolumn{4}{|l|}{ Parameters } \\
\hline Nemati et al..$^{30}$ & $0.388-13.6$ & 0.00970 & Sulfur-doped quantum dots & Soft drink \\
\hline Deng et $a .^{31}$ & $5.00-30.0$ & 1.00 & Silver nanoparticles & Soft drink \\
\hline Siering et l. $^{32}$ & $0.970-5.82$ & - & Supramolecular fluorescence & Soft drink \\
\hline Rochat et al. ${ }^{16}$ & $0-776$ & - & Cuvette & Soft drink \\
\hline Monteiro et $_{\text {al. }}{ }^{33}$ & $0.485-194$ & 0.570 & Cork-graphite sensor & Soft drink \\
\hline Present study & $100-600$ & 30.0 & Insert & Soft drink and medicines \\
\hline
\end{tabular}

obtained $p$-value $(0.883)>\alpha(0.0500)$ that demonstrates the caffeine concentrations in each sample using both methods (fluorimetric device and spectrofluorimeter) are not different statistically.

In this study, the results obtained from the digital images were compared with data reported in the literature. McCracken et $a .^{26}$ also used the HPTS fluorophore to determine caffeine in a paper-based device. In another study, McCracken et al. ${ }^{10}$ also presented a proposed fluorimeter response using HPTS for bisphenol A (BPA), estradiol and nonylphenol as a promising and low cost portable analytical alternative. In both studies, smartphone image acquisition and ImageJ software were used. However, the proposed method in this work has some advantages over the previously mentioned studies, such as a linear range broader than both cited studies and also the LOD is three times smaller than the cited studies. Table 3 illustrates a brief comparison between the proposed device and previous published papers. According to Rochat et al. ${ }^{\mathbf{1 6}}$ the reaction involving HPTS and caffeine presented the highest quenching emission compared to other compounds structurally similar to caffeine such as adenine, adenosine, ephedrine, guanosine, histidine, indole, paracetamol, phenylalanine, theobromine, theophylline, tryptophan, tyramine, tyrosine and uracil. The same authors obtained an analytical curve from 0 to $4 \mathrm{mmol} \mathrm{L}^{-1}$ which corresponds to $0-776 \mathrm{mg} \mathrm{L}^{-1}$, a similar result is obtained by the proposed method. HPTS dye presents a quantum yield varying from 0.82 to $1.00 .^{27,28}$ In the proposed method the quantum yield calculated was 0.99 .

As observed, the proposed fluorimetric device allowed the determination of caffeine by using a portable, quick and low cost device. Also, it allowed reduced reagent and sample consumption that was fifteen times smaller when compared to the fluorimeter analysis, and raised analytical frequency without using classical and expensive analytical equipment, decreasing the analysis price. The estimated analysis cost, including the system used to capture the images, was US \$1.00, not considering the smartphone cost, since it is a technology widely used. The cost raises to US $\$ 7.50$ including the optical fiber, Arduino Nano and the glass insert used in this device.

\section{Conclusions}

The proposed device proved to be a promising analytical tool to determine caffeine in commercial beverages and medicines with advantages such as being portable and low cost. The matrix effect demonstrated signal suppression for energy drink and medicine samples, and it was minimized by standard addition calibration. The linear wide range obtained for the energy beverage and medicine samples was from 100 to $600 \mathrm{mg} \mathrm{L}^{-1}$. This is an important analytical advantage for the proposed device, mainly smartphone data acquisition, which usually presents a limited work range of 100 concentration units. The proposed device is suitable to be used for caffeine determination in an energy drink and medicine samples with a reduced amount of reagent and sample consumption, requiring only $50 \mu \mathrm{L}$ of sample. Moreover, the method and fluorimetric device proposed are suitable to be used for caffeine determination in remote areas with limited analytical resources requiring only a smartphone.

\section{Conflicts of interest}

There are no conflicts of interest to declare.

\section{Acknowledgements}

The authors are grateful to Fundação de Amparo à Pesquisa do Estado de São Paulo (FAPESP number 16/03369-3, 18/22393-8 
and INCT-DATREM number 14/50945-4), Conselho Nacional de Desenvolvimento Científico e Tecnológico (CNPq) and Coordenação de Aperfeiçoamento de Pessoal de Nível Superior (CAPES).

\section{References}

1 J. Wu, J. Yue, R. Hu, Z. Yang and L. Zhang, World Acad. Sci. Eng. Technol., 2008, 44, 438-442.

2 T. G. Santos-Silva, C. C. Montagner and C. B. Martinez, Environ. Toxicol. Pharmacol., 2018, 58, 237-242.

3 L. S. Rosenfeld, J. J. Mihalov, S. J. Carlson and A. Mattia, Nutr. Rev., 2014, 72, 23-33.

4 FDA, Spilling the Beans: How Much Caffeine is Too Much?, 2019, https://www.fda.gov/ForConsumers/ ConsumerUpdates/ucm350570.htm.

5 FDA, Multiple Purpose GRAS Food Substances; Caffeine. 21 CFR Sec.182.1180, 2011, https:/www.accessdata.fda.gov/scripts/ cdrh/cfdocs/cfcfr/CFRSearch.cfm?FR=182.1180.

6 C. A. B. De Maria and R. F. Moreira, Quim. Nova, 2007, 30, 99105.

7 C. G. Ravazzi, M. d. O. K. Franco, M. C. R. Vieira and W. T. Suarez, Talanta, 2018, 189, 339-344.

8 R. S. Lamarca, N. d. C. Luchiari, A. F. Bonjorno, J. P. Filho, A. A. Cardoso and P. C. F. Lima Gomes, Anal. Methods, 2019, 11, 3697-3705.

9 L. P. d. S. Benedetti, V. B. dos Santos, T. A. Silva, E. BenedettiFilho, V. L. Martins and O. Fatibello-Filho, Anal. Methods, 2015, 7, 7568-7573.

10 K. E. McCracken, T. Tat, V. Paz and J. Y. Yoon, RSC Adv., 2017, 7, 9237-9243.

11 V. B. dos Santos, E. K. da Silva, L. M. A. D. Oliveira and W. T. Suarez, Food Chem., 2019, 285, 340-346.

12 M. A. Dominguez and M. E. Centurión, Microchem. J., 2015, 118, 110-114.

13 K. D. Pessoa, W. T. Suarez, M. F. dos Reis, M. d. O. K. Franco, R. P. L. Moreira and V. B. dos Santos, Spectrochim. Acta, Part A, 2017, 185, 310-316.

14 E. J. Lenardão, R. A. Freitag, M. J. Dabdoub, A. C. Ferreira Batista and C. Da Cruz Silveira, Quim. Nova, 2003, 26, 123129.

15 P. Anastas and N. Eghbali, Chem. Soc. Rev., 2010, 39, 301312.
16 S. Rochat, S. N. Steinmann, C. Corminboeuf and K. Severin, Chem. Commun., 2011, 47, 10584-10586.

17 M. D. Abràmoff, P. J. Magalhães and S. J. Ram, Biophot. Int., 2004, 11, 36-42.

18 U. S. Food and Drug Administration (FDA), Analytical Procedures and Methods Validation for Drugs and Biologics, 2015, pp. 1-15.

19 International Conference on Harmonisation of Technical Requirements for Registration of Pharmaceuticals for Human use - ICH, Validation of Analytical Procedures: Text and Methodology, 2005, pp. 1-17.

20 M. Gros, M. Petrović and D. Barceló, Talanta, 2006, 70, 678690.

21 M. Gros, S. Rodríguez-Mozaz and D. Barceló, J. Chromatogr. A, 2013, 1292, 173-188.

22 J. Demas, Excited State Lifetime Measurements, Academic Press, New York, 1983.

23 N. Turro, Modern Molecular Photochemistry, University Science Books, Sausalito, 1991.

24 S. Soares, M. J. Lima and F. R. Rocha, Microchem. J., 2017, 133, 195-199.

25 A. Soni, R. K. Surana and S. K. Jha, Sens. Actuators, B, 2018, 269, 346-353.

26 K. E. McCracken, S. V. Angus, K. A. Reynolds and J. Y. Yoon, Sci. Rep., 2016, 6, 27529.

27 E. B. de Borba, C. L. C. Amaral, M. J. Politi, R. Villalobos and M. S. Baptista, Langmuir, 2000, 16, 5900-5907.

28 D. B. Cordes, S. Gamsey, Z. Sharrett, A. Miller, P. Thoniyot, R. A. Wessling and B. Singaram, Langmuir, 2005, 21, 65406547.

29 S. Hernandez-Aldave, A. Tarat, J. D. McGettrick and P. Bertoncello, Nanomaterials, 2019, 9, 221.

30 F. Nemati, M. Hosseini, R. Zare-Dorabei, F. Salehnia and M. R. Ganjali, Sens. Actuators, B, 2018, 273, 25-34.

31 H. Deng, B. Wang, M. Wu, B. Deng, L. Xie and Y. Guo, Int. J. Food Sci. Technol., 2019, 54, 202-211.

32 C. Siering, B. Beermann and S. R. Waldvogel, Supramol. Chem., 2006, 18, 23-27.

33 M. K. Monteiro, S. S. Paiva, D. R. da Silva, V. J. Vilar, C. A. Martínez-Huitle and E. V. dos Santos, J. Electroanal. Chem., 2019, 839, 283-289. 